\title{
Endangering yourself to save another : A real life ethical dilemma
}

\author{
Radun, Igor
}

2019-07

Radun , I , Radun , J , Kaistinen , J , Olivier , J , Kecklund , G \& Theorell , T 2019 , ' Endangering yourself to save another : A real life ethical dilemma ', Transportation Research. Part F: Traffic Psychology and Behaviour , vol. 64 , pp. 318-322 . https://doi.org/10.1016/j.trf.2019.05.015

http://hdl.handle.net/10138/308746

https://doi.org/10.1016/j.trf.2019.05.015

cc_by_nc_nd

acceptedVersion

Downloaded from Helda, University of Helsinki institutional repository.

This is an electronic reprint of the original article.

This reprint may differ from the original in pagination and typographic detail.

Please cite the original version. 


\section{Title: Endangering yourself to save another: A real life ethical dilemma}

Authors: I. Radun ${ }^{1,2 *}$, J. Radun ${ }^{3} \dagger$, J. Kaistinen ${ }^{4}$, J. Olivier ${ }^{5,6}$, G. Kecklund ${ }^{2}$, T. Theorell ${ }^{2}$

${ }^{1}$ Department of Psychology and Logopedics, Faculty of Medicine, University of Helsinki, Helsinki, Finland.

${ }^{2}$ Stress Research Institute, Stockholm University, Stockholm, Sweden.

${ }^{3}$ Turku University of Applied Sciences, Turku, Finland.

${ }^{4}$ Liikenneturva - Finnish Road Safety Council, Helsinki, Finland.

${ }^{5}$ School of Mathematics and Statistics, University of New South Wales, Australia.

${ }^{6}$ Transport and Road Safety (TARS) Research, UNSW Sydney, Australia

$\dagger$ At the time of the data collection, this author was employed at the University of Helsinki.

Corresponding author: Igor Radun, Department of Psychology and Logopedics, Faculty of Medicine, University of Helsinki, Finland

Tel.: +358 2941 29417; E-mail address: igor.radun@helsinki.fi Home page:

http://www.mv.helsinki.fi/home/radun

Disclosure Statement: No significant financial interest/other relationship to disclose. 


\begin{abstract}
Unlike hypothetical trolley problem studies and an ongoing ethical dilemma with autonomous vehicles, road users can face similar ethical dilemmas in real life. Swerving a heavy vehicle towards the road-side in order to avoid a head-on crash with a much lighter passenger car is often the only option available which could save lives. However, running off-road increases the probability of a roll-over and endangers the life of the heavy vehicle driver. We have created an experimental survey study in which heavy vehicle drivers randomly received one of two possible scenarios. We found that responders were more likely to report they would ditch their vehicle in order to save the hypothetical driver who fell asleep than to save the driver who deliberately diverted their car towards the participant's heavy vehicle. Additionally, the higher the empathy score, the higher the probability of ditching a vehicle. Implications for autonomous vehicle programming are discussed.
\end{abstract}

Key words: trolley problem; autonomous vehicles; empathy; suicide 


\section{INTRODUCTION}

With the advancement of autonomous vehicles, the old trolley problem(Foot, 1967; Thomson 1985) has received a new dimension. Instead of asking people what they would do in a hypothetical and unrealistic situation as in trolley problem studies (e.g., if you do nothing, five people would die on the main train track, but if you divert the trolley to another track, "only" one person standing there would die), manufacturers and programmers of autonomous vehicles have to consider such possibilities in real-life situations. The vehicles have to be programmed to make ethical decisions in potentially rare situations when the harm seems unavoidable and to choose, for example, between their passengers and pedestrian(s) (Bonnefon, Shariffand Rahwan 2016). How this will be resolved and addressed in legislation is yet to be determined.

While trolley problem studies involve hypothetical, unrealistic scenarios, the ethical dilemma of autonomous vehicles, on the other hand, has become relevant only recently and is difficult to solve. However, there is also a group of road users who face similar, real life ethical dilemmas that can occur in a fraction of a second. When passenger cars collide with heavy vehicles, the passenger car occupants are much more likely to suffer serious injury than the heavy vehicle drivers due to the mass difference between these vehicles. Even if a truck driver brakes, the impact force might be so high that swerving the truck to avoid a head-on crash is often the only option which could save lives. This is well known to truck drivers, and the public often praise those who decide to swerve off road and endanger themselves (and their livelihood) in an attempt to save others from certain death (see Part 1 in supplementary materials).

In Finland, about 28 fatal crashes each year are classified as probable suicides (Airaksinen, Korpinen, and Parkkari 2016). Of these, about 24 suicides involve a motor vehicle representing about $11 \%$ of all motor vehicle fatal crashes and about 4 suicides per year involve 
pedestrians who throw themselves under a motor vehicle, representing about $13 \%$ of fatal crashes involving pedestrians (Airaksinen, Korpinenand Parkkari 2016). In the large majority of cases involving motor vehicles, car drivers commit suicide by crashing into a heavy vehicle. Other reasons why car drivers might end up crashing into a heavy vehicle are fatigue related where the driver fell asleep or where the driver suffered an acute medical condition such as a myocardial infarction, which are unintentional deaths (Jones, Dorrian and Rajaratnam 2005). In Finland, up to $15 \%$ of fatal crashes are attributed to driver fatigue (Radun 2009) and about $11 \%$ are due to disease attack (Tervo et al. 2013).

The purpose of this study was to test whether professional truck drivers' reactions (to ditch or not to ditch a vehicle in an attempt to save the driver of the oncoming vehicle) in an imaginary scenario would differ according to the state of the oncoming driver (e.g., looks like deliberate action vs. looks like the driver has fallen asleep). Possible differences between actions in two scenarios were examined in relation to empathy (Empathic Concern Scale from the Interpersonal Reactivity Index; Davies, 1980, 1983).

\section{MATERIALS AND METHODS}

\section{The survey}

Data were collected as part of a large survey on road traffic suicides collected from a sample of Finnish professional heavy vehicle drivers. The survey included questions about experience, knowledge and opinions about road traffic suicides as well as driving exposure questions and several psychological scales such as Perceived Stress Scale (Cohen, Kamarck and Mermelstein, 1983). The particular scenario question used in the present study was incorporated in the survey. Here, we report only the results from this sub-study which has a very specific aim. 


\section{The scenario}

The participants were asked to imagine a situation in which a car is slowly leaving its own lane and heading towards their vehicle on a straight section of the road. Eachparticipant received only one scenario (looks like deliberate action or looks like the driver has fallen asleep). The main focus was on this answer ("I'd not hesitate to ditch a vehicle if that would save the life of the oncoming driver"), which was listed among several multiple choices. The scenarios, the related question and offered answers are given in the supplementary materials.

Possible differences between actions in two scenarios were examined in relation to a personality measure, namely empathy (Empathic Concern Scale from the Interpersonal Reactivity Index; Davies 1980, 1983). This subscale “inquires about respondents' feelings of warmth, compassion, and concern for others" (Davies 1980). It has seven itemsand respondents have to indicate how well the item describes them on a five-point scale $(0=$ "does not describe me well"to 4="describes me very well"). Three items are reversed scored and a total score ranges from 0 to 28 .

The hypothesis was that the willingness to ditch a vehicle in an attempt to save the oncoming driver will be positively related to the empathy score and more present in the falling asleep scenario. The study protocol was approved by the University of Helsinki's Ethical Review Board in Humanities and Social and Behavioral Sciences.

\section{The sample}

We had no theoretical or practical reasons to expect a certain effect size. Therefore, we were conservative in our expectations and wanted to determine a sufficient sample size for a small 
effect size (odds ratios of 1.2 and 1.3). We run a power analysis for a logistic regression using G*Power 3.1.9.2 (Faul, Erdfelder, Buchner and Lang 2009) with alpha set to 0.05, power to 0.80 and default $\mathrm{p} 0$ value of 0.5 . We run both one- and two-tailed tests. In all combinations, the desired sample was below 1000, which corresponded to our initial aims when planning this large survey study. Therefore, with the expected response rate of $25-30 \%$, which is typical for surveys of this kind in Finland, we decided to send an invitation to 4000 heavy vehicle drivers. The sample was randomly divided into two subsamples, each receiving only one scenario

Drivers from a professional drivers' union with more than 50,000 members were invited by email to answer an online survey. The authors wrote the invitation letter, but the organization's representative sent the actual email (and one reminder) and was responsible for sampling. Based on the organization records, an attempt was made to select those who were working as heavy vehicle drivers at the time of the survey.

After one reminder, 863 drivers responded to the survey, yielding a response rate of about $22 \%$. For this analysis, we excluded those $(\mathrm{N}=79)$ who during the past three months had been mostly driving buses, passenger cars, or vehicles with the maximum allowed mass up to 3.5 tons, were unemployed, retired or were on sick or paternal leave. An additional 49drivers were excluded because of incomplete empathy scores or non-response to the scenario question. Therefore, the final sample consisted of 735drivers (357in suicide and 378 in the falling asleep scenarios; $6.7 \%$ were women). None of the responders were an entrepreneur, meaning they were all driving for someone else.

\section{Statistical analysis}


Binary logistic regression function (with a standard normal covariate) available in SPSS, version 24 for Windows, was applied in order to test whether the self-reported willingness to ditch a vehicle in an attempt to save the driver of the oncoming vehicle depended on the state (suicide vs. falling asleep) of a driver in the imaginary scenario, and on the empathy score of our respondents. The Empathic Concern Scale score was averaged (i.e., divided by the number of items-7), so that odds ratios could be interpreted as a change in the odds corresponding to a one unit increase on the average of the items or to a seven unit increase on the total score. This initial model was driven by our hypothesis. Odds ratios were adjusted by the age and sex of the respondents, and two variables/questions ("Have you ever been involved in a situation where someone tried to commit suicide by driving into your heavy vehicle or you suspected that this was the case?" and "Have you ever wondered what you would do in a situation where a driver deliberately drives his car into your vehicle?").

\section{RESULTS}

The drivers were more likely to report they would ditch their vehicle in the scenario with a driver who fell asleep $(\mathrm{OR}=1.98,95 \% \mathrm{CI}$ : 1.47-2.68; adjusted OR $(\mathrm{aOR})=1.78,95 \% \mathrm{CI}: 1.31-$ 2.43). The odds of ditching a vehicle increased by $69 \%$ for a seven unit empathy score increase $(\mathrm{OR}=1.69, \mathrm{CI}: 1.31-2.18$; adjusted $\mathrm{OR}(\mathrm{aOR})=1.65,95 \% \mathrm{CI}: 1.26-2.16)$. There was no interaction between the scenario and empathy score as indicated also in Figure 1. 


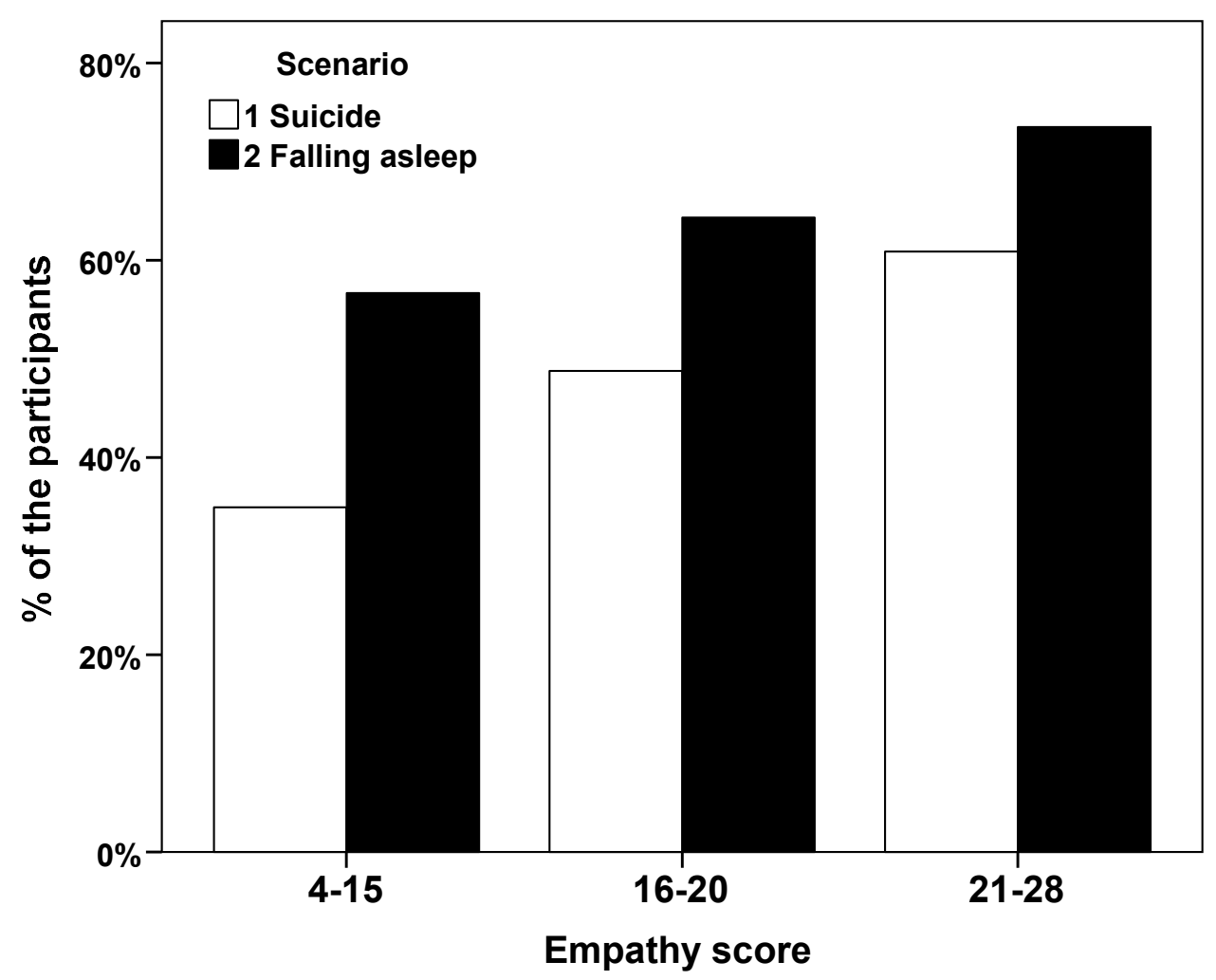

Fig. 1. The proportion of drivers that would ditch their vehicle according to the scenario and empathy score (with $26.3 \%, 45.3 \%$, and $28.4 \%$ of participants in the three empathy groups).

\section{DISCUSSION}

As expected, the survey respondents were more likely to report willingness to ditch their vehicle in order to save the hypothetical driver who fell asleep than to save the driver who apparently deliberately diverted their car towards the participant's heavy vehicle. The empathy score was also related to the willingness to ditch one's own vehicle as predicted. 
Although some would argue that these results would not be very different from what would have been predicted by common sense, it is unlikely that anybody would have predicted that the proportion of those with higher empathy score willing to ditch a vehicle in the falling asleep scenario (Fig. 1) would be twice that of those with lower empathy score for the suicide scenario $(73.5 \%$ vs. $35 \%)$.

It is well known that humans show more empathy towards those whose difficulties were the result of unfortunate circumstances than to those whose difficulties were the result of their own "wrong doing" or risk taking. For example, in one study, participants were more sensitive to the pain of AIDS patients who had contracted the disease via blood transfusion than to drug addicts who were infected when using shared needles to inject drugs (Decety, Echols andCorrell 2009). However, while human drivers can make a distinction between a teenager running across a street to catch a bus and a person who deliberately jumps in front of a vehicle, it is unclear whether autonomous vehicles would ever be able to make such judgments.

Without moralizing about whether autonomous vehicles should be able to make such judgments and act differently than humans, it is clear that our respondents do take into consideration the reasons why another road user might crash into their vehicle when they make a decision whether to endanger their own life or not. Certainly, those who attempt to end their life by jumping or steering their vehicle in front of somebody's vehicle are in serious distress and need help from those close to them and from society in general. However, it raises the question as to whether one has to endanger one's own life in an attempt to save them. As Huebner and Hauser (2011, p. 74) write, “Altruistic self-sacrifice is rare, supererogatory, and not to be expected of any rational agent" (italics original). 
Therefore, it is unreasonable to expect that one has to endanger one's own life in any circumstance (see Part 2 in supplementary materials). Accordingly, it would seem unfair to blame a heavy vehicle driver who drives according to the speed limit and "only" slams on the brakes when a person deliberately jumps or steer their vehicle in front of his vehicle as he is unwilling to swerve to the left into the oncoming vehicle or to the right into trees. This might sound like a very rare situation, but for heavy vehicle drivers, at least in Finland, it is far from a hypothetical scenario. Furthermore, there are many documented cases of pedestrians throwing themselves in front of slow- moving cars in order to make compensation claims. There are some estimates that such so-called crash-for-cash insurance scams are on the rise(Button and Graham 2016). A Video Event Data Recorder (VEDR), which may be installed in autonomous vehicles, can provide liability protection in crash-for-cash scams and can reduce their occurrence, but is not relevant at all for suicide cases. These will continue to happen regardless of how autonomous vehicles are programmed.

This study has several limitations including a low response rate. In fact, the exact response rate is unclear as it was not possible to verify the accuracy of the union's records regarding the type of job their members had at the time. Furthermore, the accuracy of current email addresses was not verifiable. Therefore, it is possible that the actual response rate was much higher. Nevertheless, with more than 350 participants in each scenario and a full range of empathy scores (4-28), it was possible to reach sound conclusions based on the study design. However, there is always a question whether the results from this survey directly translate to real world situations. Such criticism is especially justified in hypothetical and unrealistic trolley problem scenarios. The scenario presented earlier to survey respondents, on the other hand, is relevant as respondents might indeed face such dilemmas in real life. 
Once all vehicles are fully autonomous on roads, it may become more difficult to commit suicide using such a vehicle; however, it seems it will take decades before all vehicles are autonomous. On the other hand, the problem of pedestrians throwing themselves in front of heavy vehicles will probably remain although automated brake assist will likely reduce both the number of incidents and crash severity. How and whether possible suicides in road traffic will be addressed in autonomous vehicle programming is yet to be seen.

Acknowledgments. The authors thank Mr. PasiRitokoski for his help in data collection and the survey respondents for taking part in this study. The authors are also grateful to DrsSointuLeikas and Marjaana Lindeman for their valuable advice in the planning stage of this study. This study was supported in full by the Finnish Work Environment Fund (decision no: 115438), the Finnish Transport Safety Agency (Trafi) and the University of Helsinki. This funding is greatly acknowledged. The first author received the H. J. Eysenck Memorial Fund Award for this study in 2017. The manuscript was finalized during Dr. Radun's visit to Stress Research Institute, Stockholm University, Sweden. This trip was supported by SvenskTrafikmedicinskFörening.

\section{REFERENCES:}

Airaksinen, N., Korpinen, A., \& Parkkari, I. (2016). Tie - ja raideliikenteen itsemurhat.

Esiselvitys. [Suicides in road and rail traffic. Feasibility study.] Research reports of the Finnish Transport Agency 7/2016. 
Bonnefon, J.-F., Shariff, A., \&Rahwan, I. (2016). The social dilemma of autonomous vehicles. Science, 352, 1573-1576.

Button, M., Graham, B. (2016). From 'shallow' to ‘deep' policing: ‘crash for-cash' insurance fraud investigation in England and Wales and the need for greater regulation. Policing and Society, 26, 210-229

Cohen, S., Kamarck, T.,\&Mermelstein, R. (1983). A global measure of perceived stress. Journal of Health and Social Behavior, 24, 385-396.

Davis, M. H. (1980). A multidimensional approach to individual differences in empathy. JSAS Catalog of Selected Documents in Psychology, 10, 85.

Davis, M. (1983). Measuring individual differences in empathy: Evidence for a multidimensional approach. Journal of Personality and Social Psychology, 44, 113-126.

Decety, J., Echols, S. C., \&Correll, J. (2009). The blame game: The effect of responsibility and social stigma on empathy for pain. Journal of Cognitive Neuroscience, 22, 985-997.

Faul, F., Erdfelder, E., Buchner, A., \& Lang, A.-G. (2009). Statistical power analyses using G*Power 3.1: Tests for correlation and regression analyses. Behavior Research Methods, 41, $1149-1160$. 
Foot, P. (1967). The Problem of Abortion and the Doctrine of the Double Effect. Oxford Review, $5,5-15$.

Huebner, B.,\& Hauser, M.D. (2011). Moral judgments about altruistic self-sacrifice: When philosophical and folk intuitions clash. Philosophical Psychology, 24, 73-94.

Jones, C.B., Dorrian, J., Rajaratnam, S.M.W. (2005). Fatigue and the criminal law. Industrial Health 4, 63-70.

Radun, I. (2009). Fatigued driving: Prevalence, risk factors and groups, and the law [Doctoral thesis]. Helsinki University Printing House, Helsinki.

Tervo, T., Räty, E., Sulander, P., Holopainen, J.M., Jaakkola. T., et al. (2013). Sudden death at the wheel due to a disease attack. Traffic Injury Prevention, 14, 138-144.

Thomson, J.J. (1985). The trolley problem. TheYale Law Journal, 94, 1395-1415. 


\section{Supplementary Materials for}

Endangering yourself to save another: A real life ethical dilemma 


\section{$\underline{\text { The scenario }}$}

Please read and answer the following question.

You are driving on a long straight section of a dual carriageway road outside an urban area. You can see from a distance that a passenger car is approaching. As it gets closer you notice that it is traveling somewhat above the speed limit $(100 \mathrm{~km} / \mathrm{h})$ and close to the centerline. Otherwise nothing seems unusual, including the driving conditions of a normal summer afternoon. At a distance of a few hundred meters, the oncoming vehicle starts (slowly) drifting across the centerline and into the path of your truck. You notice that the oncoming driver is sitting normally, is looking directly at you, and doesn't seem to be wearing a seat belt (OPTION 1) / the opposite driver appears to be asleep, seems to be wearing a seat belt, and his head has nodded forward (OPTION 2).

What would you do in this situation? (multiple choice)

$\square$ I'd warn him with the lights/horn

If he didn't respond, I'd brake forcefully

If he didn't respond, I'd try to swerve

$\square$ I'd not hesitate to ditch my vehicle if that would save the life of the oncoming driver 


\section{$\underline{\text { Part }} \underline{1}$}

In a very recent case, a passenger car driver fell asleep, his car crossed the centerline and was heading towards an oncoming truck. The truck driver decided to go off the road to prevent a crash. A crash did occur, as the car hit the rear of the truck, but its severity was reduced as headon collision was avoided (Heino, 2015). The actions of the truck driver were welcomed by the media, especially given the fact that no lives were lost, including that of a three-year-old in the passenger car (e.g., "Tragic head-on collision closely averted - truck driver luckily manages to swerve into a ditch”) (Von Bell, 2015).

\section{$\underline{\text { Part }} \underline{2}$}

A comment posted in a daily newspaper (Iltalehti) site by a professional truck driver summarizes the dilemma that truck drivers might have in similar cases. He wrote: “...this is the kind of news that makes you think what you would do if someone drives straight at you. Yes, I'd brake, but I'd not put a $€ 300,000$ trailer into a ditch on its roof. In fact, you get prosecuted if you 'intentionally' ditch a vehicle, as in this case. Fortunately, however, the lives were saved.'

\section{References}

Heino, J. (2015, July 20). Miesnukahtirattiin - seitsemänloukkaantuneenjoukossa 3-vuotias lapsi [The man fell asleep at the wheel - 3-year-old-child among seven injured]. Retrieved from: http://www.iltalehti.fi/uutiset/2015072020064171_uu.shtml 
Von Bell, C. (2015). Traaginennokkakolarihyvinlähellä - onneksirekkakuskiehtiväistääojaan

[Tragic head-on collision closely averted - truck driver luckily manages to swerve into a ditch].

Uuusi Suomi. Retreived from: http://www.uusisuomi.fi/autot/91631-traaginen-nokkakolari-

hyvin-lahella-onneksi-rekkakuski-ehti-vaistaa-ojaan 